MPC MAJOR RESEARCH PAPER

What is there to Yelp About?

SARA ROSENFELD

\author{
Joanne DiNova \\ Ryerson University
}

The Major Research Paper is submitted

in partial fulfillment of the requirements for the degree of

Master of Professional Communication

Ryerson University

Toronto, Ontario, Canada

August 31, 2011 


\section{WHAT IS THERE TO YELP ABOUT?}

\section{Appendix E: MPC MRP Author's Declaration Page}

I hereby declare that I am the sole author of this Major Research Paper.

I authorize Ryerson University to lend this MRP to other institutions or individuals for the purpose of scholarly research.

Signature

I further authorize Ryerson University to reproduce this MRP by photocopying or by other means, in total or in part, at the request of other institutions or individuals for the purpose of scholarly research.

Signature 
WHAT IS THERE TO YELP ABOUT?

\begin{abstract}
This paper examines the use of language in user generated online product reviews on the website Yelp.ca. Using both Relevance Theory and the Co-operative Principle this study identifies nine linguistic devices to analyze within restaurant reviews on this website. Yelp.ca administrators identify some reviewers as "Elite Reviewers." This study contrasted twenty-five Elite reviews with twenty-five Non-Elite reviews in order to determine which linguistic devices were more prevalent within Elite reviews. The findings illustrate that there are concrete differences between these two types of reviews. Assuming that Elite Reviews are in fact more persuasive, these findings suggest that there may be concrete attributes of a review that make it more persuasive in an online, user generated context.
\end{abstract}


WHAT IS THERE TO YELP ABOUT?

\section{ACKNOWLEDGEMENTS}

It is a pleasure to thank those who made this thesis possible. I owe my deepest gratitude to both my first and second reader, Dr. Joanne DiNova and Dr. Wendy Freeman, who provided me with their time, input, and wisdom during these busy summer months. Without their continual support and cooperation this MRP would not have been possible.

Sara Rosenfeld 
WHAT IS THERE TO YELP ABOUT?

\section{TABLE OF CONTENTS}

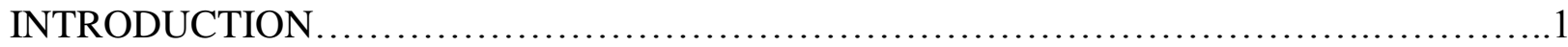

LITERATURE REVIEW ..........................................................

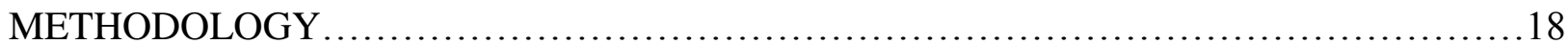

ANALYSIS \& INTERPRETATION .................................................. 27

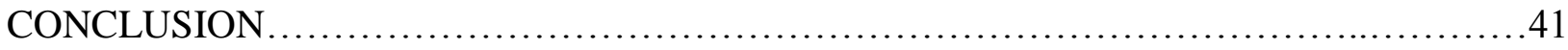

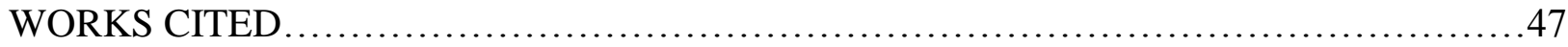

\section{LIST OF FIGURES}

Figure 1: Non-Elite Review Example..............................................4

Figure 2: Elite Review Example $\ldots \ldots \ldots \ldots \ldots \ldots \ldots \ldots \ldots \ldots \ldots \ldots \ldots \ldots \ldots \ldots \ldots \ldots \ldots \ldots \ldots \ldots 4$

Figure 3: Gee's Discourse Analysis Tools (Gee, 2011)..................................19

Figure 4: Illustration of Elite and Non Elite Review Findings of Linguistic Devices...............27

Figure 5: Illustration of Elite and Non-Elite Word Count................................28

Figure 6: Average Elite and Non-Elite Review.....................................40 


\section{INTRODUCTION}

Restaurant reviews, a unique and persuasive genre of text, have evolved through a variety of forms with a diverse set of authors. Primarily, these reviews serve to inform and persuade; yet they have additionally served a variety of sociological and linguistic functions not encapsulated within this set definition. Word of mouth reviews may serve as a means for individuals to socialize, providing a topic of casual conversation amongst acquaintances. Professional reviewers often develop a cult following, serving to create and strengthen social groups for avid foodies. Online reviews may serve as a forum for business owners to surreptitiously promote their companies, disgruntled patrons or competitors to vent their frustrations or tarnish a competitor's reputation, or for the average consumer to ensure their voice is heard and mark is made in this digital age. For these reasons, when consumers seek information about a restaurant, they are offered an immeasurable quantity of competing information; from the establishment's promotional materials, word of mouth through friends and family, and a multitude of potentially contradictory user reviews on various restaurant review websites. With these high levels of competing information, it becomes increasingly important to those writing the reviews that they provide information that is both easy for the user to understand and is of high quality; in other words, information that is maximally relevant. This study will contrast online restaurant reviews on the website Yelp categorized as written by Elite users with those written by Non-Elite users using Relevance Theory and the Co-operative Principle in order to identify differences within linguistic devices between the two categories of reviews.

This comparison was accomplished by conducting a discourse analysis of the restaurant reviews posted on the online review website Yelp.ca in order to determine which linguistic 


\section{WHAT IS THERE TO YELP ABOUT?}

devices within Elite reviews make them more persuasive. Using Relevance Theory and the Cooperative principle to identify review attributes, the study attempts to identify qualitative differences between reviews written by those deemed more persuasive by the Yelp administrators (Elite reviewers) and other reviewers (Non-Elite reviewers).

This website, herein referred to as Yelp, is an innovative platform that displays attributes of a variety of currently existing genres: restaurant reviews and multiple social media platforms. There are many attributes of Yelp that parallel aspects of social media websites such as Twitter and Facebook, including detailed personal profiles of reviewers and the ability to "friend" and "follow" reviewers. Restaurant reviews are the primary use of the website although it offers a variety of business reviews, and for this reason Yelp illustrates many aspects of the restaurant review genre. Yelp reviews contain a variety of functions and methods of representing each users experience at a business. Along with each written review, reviewers attribute a star rating to their experience, one being the lowest and five being the highest. The incorporation of social media into restaurant reviews makes this genre different from traditional reviews as it allows it to be in a continual state of evolution as new reviews are added as well as intrinsically alters the methods with which credibility is established by those posting these reviews. The establishment of credibility is one of many attributes of the reviews that follow one of the maxims of the Cooperative Principle: the maxim of relation. The importance of each of these maxims and the Cooperative Principle, one of two theories that were utilized to design the methodology, will be discussed at length later in this study. Each of these maxims has the ability to strongly alter the effectiveness of the restaurant review.

In order to create a hierarchy, Yelp administrators have defined some users as "Elite Squad Reviewers" or Elite reviewers. Though review readers have the ability to vote on user 


\section{WHAT IS THERE TO YELP ABOUT?}

profiles, ranking their reviews with a variety of attributes such as "useful" or "funny" it is ultimately a top-down decision in which the administrators of Yelp select Elite reviewers. Though this is contradictory to the concept of user-generated information, it allows for a certain level of control as it is a consistent group of individuals selecting Elite reviewers. These reviewers attain this status through submitting their profiles to the administrators of the Yelp website for consideration. The administrators then select users who have highly informative profiles, a high quantity of reviews that are both informative and entertaining, and "personal pizzazz" to join the Elite Squad Reviewer team. On the Yelp Elite Squad Page administrators state that they value reviews that are especially useful and personal (Yelp, 2011). There are also concrete reviewer attributes that must be in place for Elite status to be attained such the use of the reviewer's real name and photo. The reviewer must also be of legal drinking age. This study attempted to illustrate that there are concrete aspects of these Elite restaurant reviews that increase their persuasiveness beyond the vague definition provided by Yelp Administrators. This was accomplished by comparing twenty-five reviews written by Non-Elite members (general users), and twenty-five reviews written by Elite members, looking for specific linguistic devices embedded within these reviews. Examples of two reviews of similar lengths and from the four star rating category can be seen as Figure 1.0 and Figure 2.0. 
WHAT IS THERE TO YELP ABOUT?

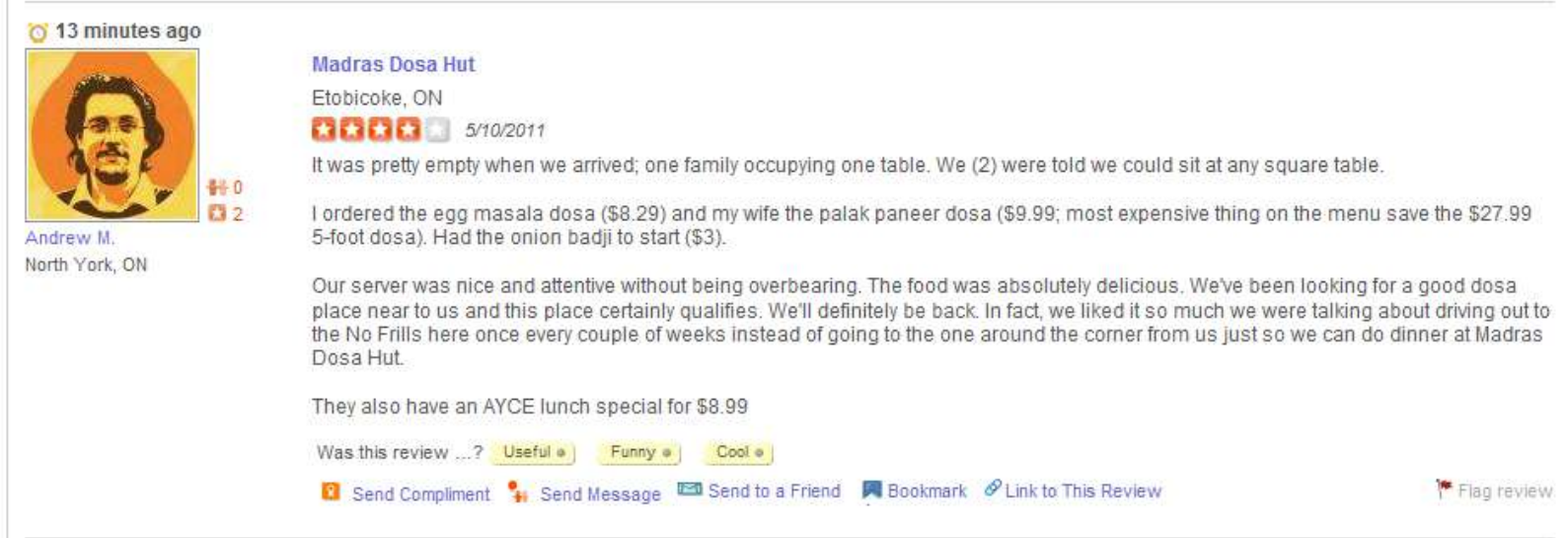

Figure 1. Non-Elite Review Example

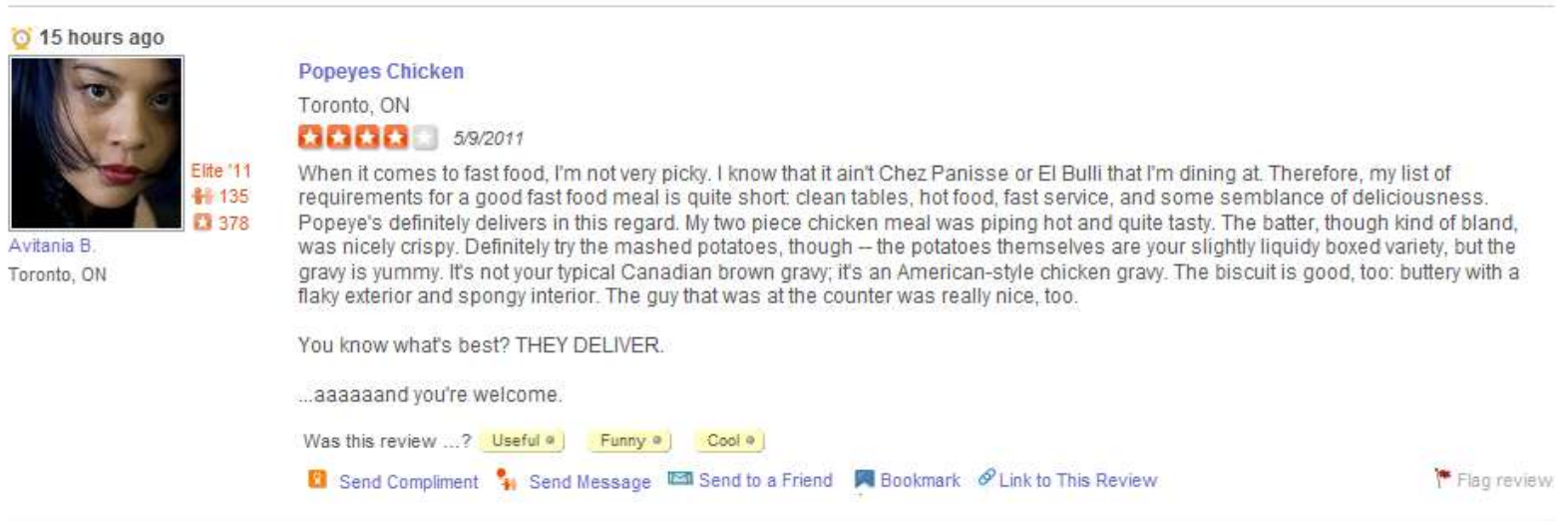

Figure 2. Elite Review Example

This study identified specific linguistic devices, chosen based on attributes identified in Relevance theory and the Co-operative Principle, in order to determine which qualitative differences exist between Elite reviews and Non-Elite reviews. Relevance Theory and the CoOperative Principle are the two theories utilized in the design of the methodology of this study, and both are discussed at length in the Literature Review section. This process established whether Elite member reviews are using more "persuasive, informative, and entertaining" tactics, as defined by the Elite Squad member selection process or if there are concrete aspects of a restaurant review written by a non-professional that make some superior to others. 


\section{WHAT IS THERE TO YELP ABOUT?}

The findings of this study will be important in the future if previously existing genres continue to incorporate aspects of social media, as it may provide a fuller understanding of the importance of incorporating additional user information into a platform. Marketing and public relations professionals can strategically use this information to better manage the online presence of those they represent, and individuals writing these reviews can utilize this information to write more persuasive reviews. This study aims to identify whether what Yelp identifies as "pizzazz" is instead concrete review attributes that ultimately lead to a more persuasive review. As the internet is flooded with business reviews, particularly restaurant reviews, it becomes important for a variety of audiences to understand what makes these reviews persuasive. For those in the hospitality industry, such as restaurateurs, whose businesses can be heavily affected by the high level of influence these reviews carry, a thorough understanding of what makes these reviews persuasive is imperative.

This study applied Relevance Theory and the Co-operative Principle to determine which linguistic devices to identify within the discourse analysis. Relevance theory, originally proposed by Sperber and Wilson, stems from Grice's model, the Cooperative Principle. Taking root in pragmatics, Relevance Theory attempts to define one maxim in which all discourse can be judged: the maxim of relevance (Cutting, 2008). Pragmatics and discourse analysis both analyze discourse through examining context and function, yet discourse analysis focuses on the structure of a text whereas pragmatics emphasizes the social principles (or norms) of a discourse.

Relevance Theory states that relevance is determined with two inputs: contextual effects and processing efforts. Contextual effects refer to the level of new information that will affect the user's judgement that is provided by an input, whereas processing efforts refer to the level of difficulty in deciphering an input. Alternately, the Cooperative Principle identifies four maxims 


\section{WHAT IS THERE TO YELP ABOUT?}

in which discourse can be judged: quality, quantity, relation, and manner (Cutting, 2008). The maxim of quality refers to whether information is true, the maxim of quantity refers to the level of information provided, the maxim of relation ensures the information comes from a credible source and has clear connections to the topic at hand, and the maxim of manner refers to the clarity of the information.

These theories are ideal to analyze the discourse of Yelp as they allowed for the identification of linguistic devices within the reviews that are specific to each attribute (descriptive vs. indefinite adjectives, personal pronouns, and credibility statements). This study aims to illustrate that each of these linguistic devices had the potential to aid or detract from the ability of the reviewer to create a relevant and persuasive restaurant review. Descriptive adjectives provide more concrete detail than indefinite adjectives, likely increasing contextual effects. Second-person personal pronouns provide information that is heavily directed towards the audience and therefore the contextual information may be perceived as more applicable by the user. Credibility statements are likely to strengthen existing information by allowing the user to increase their confidence in the information provided; though if not paired with the other persuasive linguistic devices these statements could be viewed as compensatory devices.

Further, a high quantity of information that does not meet the above criteria is likely to lower the level of relevance by increasing the processing effort required without increasing the contextual effects.

The first linguistic devices analyzed within the documents, the Yelp restaurant reviews, is the use of descriptive vs. indefinite adjectives. Descriptive adjectives are defined for the purposes of this study as a basic form of adjective that provides useful and informative supporting details. These fall into categories such as color, size, quality, or time to name a few 


\section{WHAT IS THERE TO YELP ABOUT?}

examples. Descriptive adjectives were defined for the purposes of this paper as adjectives that provide strong supporting details of the reviewer's experience or the food quality. Examples of descriptive adjectives are "neon color of the chicken" and "this portion is large enough to feed two." Alternately, indefinite adjectives were considered adjectives that are vague and do not point out any tangible attributes. These adjectives provide little to no supporting detail to the reader. An example is "there were several options on the menu." This study analyzed the application of these adjectives within both Elite and Non-Elite reviews to determine whether there is a difference in quantity and type of adjective used.

The next linguistic device used to analyze the online restaurant reviews was first, second, and third-person personal pronouns. Personal pronouns can be singular or plural, male, female, or gender neutral, and are used in place of an individual or group of individuals. An example of a first-person personal pronoun is "I" or "me", and these terms are used when referring to oneself. An example of a second-person personal pronoun is "you". Second-person personal pronouns are used when referring to the reader. An example of a third-person personal pronoun is "she" or "it" and these terms are used when referring to something/someone separate from the reader or writer. A comparison of the use of first, second, and third-person personal pronouns between Elite squad reviews and Non-Elite reviews on Yelp was conducted in order to determine whether there was a difference between quantity of personal pronouns used as well as type (first, second, or third-person).

Lastly, this study sought to identify credibility statements and non-credibility statements within these reviews. Credibility statements are phrases in which the author expresses some form of authority on the subject matter. These statements do not have to be direct claims, and are often embedded indirectly into reviews in forms such as descriptions of reviews previously 


\section{WHAT IS THERE TO YELP ABOUT?}

posted, or restaurants frequently visited. Any statements discussing previous reviews or knowledge regarding other restaurants were considered indirect credibility statements. Statements referring to Yelp Elite status, or directly stating credibility or familiarity with a genre of food were considered direct credibility statements. An example of a direct credibility statement is "I know a lot about Chinese food; since I grew up eating it" whereas an example of an indirect credibility statement is "The food was not as good as at the restaurant down the street." Non-credibility statements were considered statements that reference the reviewer's lack of knowledge or confidence in their review. Statements such as "I don't know" or "you decide" were considered direct non-credibility-statements; whereas "This was my first time eating Thai food" would be considered an example of indirect non-credibility statements.

In an attempt to learn more about the genre of user-written online restaurant reviews, this study began with the research question:

What can the tools of discourse analysis tell us about the evolution of the genre of restaurant reviews as it moves into an online and user-generated context? 


\section{WHAT IS THERE TO YELP ABOUT?}

\section{LITERATURE REVIEW}

The literature surveyed encompasses key concepts of this study with an emphasis on persuasiveness and credibility in online environments, as well as a theoretical orientation with Relevance Theory and the Co-operative Principle. The first theme identified is the importance of electronic product reviews to consumers when making purchasing decisions. While this is not the emphasis of this study, it helps to provide a situational context for the research. This theme is highly relevant as it illustrates the importance of increased research into electronic restaurant reviews due to their high level of influence on purchasing decisions. The second theme is that of persuasiveness in language. These articles examine a variety of textual genres, including emails, social media, and online product reviews. Each article provides an analysis of the persuasive tactics utilized through a different electronic medium.

This study applies Relevance Theory and the Co-operative Principle to the design of the discourse analysis. Relevance theory, originally proposed by Sperber and Wilson in 1982, stems from Grice's Cooperative Principle, created in 1975. Relevance theory attempts to approach two of Grice's central claims from an alternative perspective. These claims are that "an essential feature of most human communication is the expression and recognition of intentions" (Wilson \& Sperber, 2003 p. 607) and that "utterances automatically create expectations which guide the hearer towards the speaker's meaning” (Wilson \& Sperber, 2003, p. 607). Relevance Theory argues that relevance is created through information that is both precise and predictable enough to allow the listener to understand the speaker's meaning. However, due to the high level of availability of information, it is not enough for information to be relevant; it must be the most relevant information available to remain competitive. For this reason, Relevance Theory articulates that each input must be more relevant than all alternative inputs. The theory expands 


\section{WHAT IS THERE TO YELP ABOUT?}

upon this premise by elaborating that the more useful the conclusions that can be drawn from an input, the more relevant it is (Wilson \& Sperber, 2003). This is particularly important in the genre of online restaurant reviews, which are plentiful and widely available. When attempting to gain information regarding a restaurant, individuals have a variety of options at their disposal. Information can be retrieved through official restaurant promotional information, traditional word-of-mouth advertising, professional reviewers, or any number of online review websites. With such high quantities of competing information, only the most relevant of reviews, those with the most useful conclusions drawn from each input, will be considered to have a high level of relevance to the user. Reviews that are considered to have a high level of relevance will likely be utilized by a variety of users, whereas those with a low level of relevance will drift into disuse quickly and be replaced by more relevant information.

Relevance Theory identifies two key effects as having a weighted impact on each input's relevance: positive cognitive effects and processing effects. Cognitive effects come in the form of any input that may inform the user; in the case of online restaurant reviews these inputs would be considered text. These effects provide users with background information necessary to properly form conclusions. Positive cognitive effects provide users with information that changes their concept of a situation, ultimately leading them to a true conclusion. As false conclusions or untrue information is unhelpful to the user, this information would be considered to lead to negative cognitive effects, and these effects are not a desired effect of communication. Positive cognitive effects clearly differentiate between information that seems relevant from information that actually is relevant from the audience's point of view (Wilson \& Sperber, 2003).

Processing effort describes the level of mental exertion required to process an input. Processing effort is generally viewed in a comparative rather than quantitative lens, and 


\section{WHAT IS THERE TO YELP ABOUT?}

comparisons are generally done subconsciously as the effort required to consciously contrast the level of mental exertion would only serve to increase the processing effort. Though it is occasionally possible to attribute quantitative comparisons to reviews if the audience chose to do so, this process is largely done in an intuitive manner, as our cognitive systems have evolved towards an automatic tendency to maximize relevance. Other things being equal, the higher the processing effort required, the less relevant an input is (Wilson \& Sperber, 2003).

Sperber and Wilson argue that in instances in which similar levels of effort are required to decipher an input, the cognitive effect of the input is the deciding factor in determining the inputs relevance. Alternately, in situations in which each input will result in a similar cognitive effect, the level of processing effort required will determine the input's relevance (2003).

Relevance Theory argues that this is a largely unconscious process due to the fact that consciously attempting to weight each input against alternate inputs would significantly increase processing effects, which humans are evolutionarily hardwired to attempt to decrease (Wilson \& Sperber, 2003). Instead, humans intuitively search for the most relevant information on an unconscious level. As such, the restaurant reviews must ensure they are maximally relevant though providing high levels of true and useful information without cluttering the reviews with unnecessary information. This is done to ensure that each review is easy to process in order to compete with the high quantities of information available to users.

Originally inspiring Sperber and Wilson's Relevance Theory, Grice's Co-operative Principle identified the concepts of processing efforts and information retrieval within his four maxims. These include the maxim of quality (factual inputs), the maxim of quantity (educative inputs), the maxim of relation (applicable inputs), and the maxim of manner (explicit inputs) 


\section{WHAT IS THERE TO YELP ABOUT?}

(Wilson \& Sperber, 2003). The maxim of quality refers to ensuring that information is true.

This maxim is often violated intentionally in cases of hyperbole, sarcasm, irony, and a variety of other linguistic devices. The maxim of quantity refers to the level of information provided, and both too much and too little information can be viewed as detracting from an inputs relevance. The maxim of relation refers to the applicability of an input to the conversation or type of information being sought by the user. The maxim of manner refers to the clarity or ease of deciphering an input. It is clear that Relevance Theory's two principles articulate many of these maxims, yet the necessity of branching from the Co-operative Principle to Relevance Theory was clear for Sperber and Wilson. Largely, Relevance Theory stemmed from issues created within the maxim of quality, or truthfulness. There exists a variety of linguistic devices, including metaphor, irony, and hyperbole, in which information provided is intentionally untrue, artificially impacting the maxim of quality. Further, Sperber and Wilson point to loose uses of language as a large issue when attempting to apply the maxim of quality. Loose uses of language refer to instances in which the explicitly laid out "exceptions" are not being utilized, yet the information is not entirely factual. An example of a loose use of language would be the use of the term "Kleenex," which is generally assumed to mean any brand of facial tissue, not necessarily Kleenex brand facial tissue (Wilson \& Sperber, 2003). Claiming to need a "Kleenex" when one really needs a facial tissue would not be considered intentionally misleading or affect the relevance of a statement, even if the statement was not entirely factual. These linguistic devices, though not necessarily untrue, do not affect processing efforts or increase or decrease positive cognitive effects. As such, Sperber and Wilson argue that Relevance Theory is a more applicable method of analysing information (2003). 


\section{WHAT IS THERE TO YELP ABOUT?}

Beyond a theoretical orientation, an analysis of current literature also provided insights into the impact of product reviews on purchasing intention, as well as a study of persuasive uses of language in online environments. In a study published in 2007, Park, Lee, and Han analyzed the factors of quality and quantity of online product reviews for their ability to influence consumer purchasing decisions. Ultimately, this quantitative study concluded that consumer purchasing intention increased with both quality and quantity of reviews. The study used the elaboration likelihood model to determine that consumers who were considered to have low levels of involvement in the product review process were heavily influenced by the quantity of reviews, whereas consumers with high levels of involvement with the product review process were heavily influenced by quality of reviews (Park, Lee, \& Han, 2007). The importance of Park, Lee, and Han's study to this research is twofold. Primarily, this study illustrates the concrete effect online product reviews have on purchasing intentions. Acting as both a source of information and mode of persuasion, online reviews are cited as being increasingly popular due to the increased trust of information source, more user-oriented information, and the provision of subjective information (Park, Lee, \& Han, 2007). Secondly, this study operationalized a definition of what makes a review of "high quality," describing high quality as reviews that are more logical and persuasive due to the fact that they are based on concrete facts rather than emotion. Though this differs from the determinants being used to define quality in this study, being reviewers identified by Yelp, it provides an alternative definition that may help identify why the administrators of Yelp chose to label these reviewers as producing high quality reviews. As this study will be identifying factors that differentiate Elite reviews from other Yelp reviews, these factors had the potential to repeat themselves as having higher prevalence amongst Elite reviews than Non-Elite reviews. Particularly, this study sought to identify whether the 


\section{WHAT IS THERE TO YELP ABOUT?}

importance of providing reviews based on fact rather than emotion was likely to repeat itself in the form of descriptive adjectives in Yelp Elite reviews.

As one of the attributes that determines quality as defined by Park, Lee, and Han, persuasiveness is described through a variety of components and definitions. Persuasiveness is one of the key aims of online restaurant reviews, and the primary way the success of online reviews is determined. Determinants of persuasiveness are illustrated in the below articles and include culture-specific persuasion techniques and credibility of the reviewer, particularly using social media or social ties to establish both familiarity and credibility (Steffes \& Burgee, 2008).

The importance of persuasion techniques that are culture specific is especially important, as culture heavily impacts the interpretation of information. In a 2010 study, Cheung compared 40 Chinese and 40 English direct marketing e-mails for persuasiveness. As these were direct marketing e-mails, their ultimate goal was to be persuasive. Further, as e-mail was utilized, this study was limited to an electronic form of communication, increasing its applicability to this study. Many differences were noted between the two styles of communication within this study. Conclusions illustrated that different conversation styles, speed of reward offerings, levels of directness, and methods of building rapport were utilized in English versus Chinese direct marketing e-mails (Cheung, 2010). Cheung's study drew attention to the scope of the application of this study, as the persuasive styles that are considered effective may be limited to a smaller arena than previously considered. In particular, Toronto is in a unique situation in this regard due to its highly multicultural population. Though each of the reviews in the data set was originally posted in English, many of them are written by users who are very likely from a variety of ethnic, cultural, and religious backgrounds. Identification of the first language of these reviewers, or their cultural upbringing, was not incorporated into this study. These factors may 


\section{WHAT IS THERE TO YELP ABOUT?}

heavily influence what persuasion styles are utilized by the reviewers, heavily influencing the data set. However, as each review is from a Toronto restaurant, the data set was treated as a whole, representative of the highly multicultural city of Toronto and its online restaurant reviewers. Attention, however, should be drawn to the ability of cultural differences to affect the maxim of relation due to perceived similarity, the maxim of manner due to differing cultural norms regarding appropriate methods of presenting information, and the maxim of quality as varying cultures have different cultural perceptions regarding what information is appropriate information to share.

Reviewer credibility is another aspect of persuasiveness that has a high level of relevance to this study as it supports the maxim of relation. Though the emphasis of this study is on persuasiveness, credibility statements and non-credibility statements have been deemed to be an important factor in the persuasiveness of an online review. As such, the 2009 study by Cheung, Luo, Sia, and Chen regarding credibility in electronic word of mouth forums has high levels of applicability to this study. Electronic word of mouth, or e-wom, refers to the passing of information, generally in the form of a recommendation, in an online setting. In a study by Cheung et al., readers of online product reviews in China were surveyed to determine how informational and normative determinants influence the perceived credibility of product reviews in online forums. The results of this study indicated that three information based attributes, namely argument strength, source credibility, and the confirmation of previously held beliefs, as well as two normative attributes, namely consistency and recommendation rating, all significantly influenced the perceived credibility of the review author (Cheung et al., 2009). Both the informational and normative attributes are highly applicable to Relevance Theory and Grice's Co-operative Principle. The informational attributes heavily affect contextual effects, as 


\section{WHAT IS THERE TO YELP ABOUT?}

they alter the usability of the data. Normative attributes affect contextual effects, or the level of relevant information provided, as well as processing effort, as incongruent data would lead to unreliability of this data, causing the reader to look further for more information, increasing processing effects and decreasing the relevance of the data provided. The study by Cheung et al. serves to illustrate the importance of attaining credibility, as well as one method of defining reviewer credibility. Though this study will analyse credibility statements rather than perceived credibility, both serve to influence the authority the reviewer holds over his or her readers and points towards the influence of perceived credibility on persuasiveness.

One influence on credibility is the use of social relationships to create familiarity. Studies regarding the importance of social relationships and online reviews do exist, though their scope is different from this study. In a 2008 study conducted by Steffes and Burgee, online and offline word of mouth were compared in order to asses which method of recommendation was more persuasive. Using the review website Rate My Professor, Steffes and Burgee contrasted the level of influence of anonymous reviewers (electronic word of mouth) with recommendations from classmates and friends (traditional word of mouth). Traditional word of mouth is similar to electronic word of mouth, except that these recommendations are provided in a face to face environment or over another communication medium between two individuals who already know each other. This study concluded that personal experience and anonymous reviewers held more influence than friends or academic advisors (traditional word of mouth). Further, the study concluded that Rate My Professor was being utilized by students as a persuasive source rather than as a source of entertainment (Steffes \& Burgee, 2008). Steffes and Burgee's study has important applications to this research, as it examines the importance of social relationships and product reviews. However, it differs from this study in one key regard. In the Steffes and 


\section{WHAT IS THERE TO YELP ABOUT?}

Burgee study, social ties are separated from electronic product reviews as two distinct categories; in this study social relationships are being incorporated into online restaurant reviews, forming a new genre of electronic word of mouth. In both instances, the importance of the maxim of relation is being studied. However, it appears that relation can be created through specific attributes of the reviews, or the reviewer profiles.

The relationship between social media websites and word of mouth has been further explored by Chu and Kim in a 2011 study. This recent study examined the use of social media websites such as Facebook and Twitter to provide a platform for discussions regarding products or services. As such, this study focused on electronic word of mouth behaviour on social media websites. Conclusions illustrated that strength of ties to those providing information did not affect persuasiveness, though levels of trust in the source did affect persuasiveness. Further, this study illustrated that interpersonal influence on social media websites was shown to affect levels of engagement felt by users (Chu \& Kim, 2011). These findings support previous research that illustrates that it is trust, not social relationships, which increases credibility. This attribute is emphasized heavily on Yelp, where users create detailed profiles to support their reviews and establish credibility for other website users externally from their reviews for review readers. Ultimately, Chu and Kim's study shows many similarities to this research project. This study clearly illustrates the importance of social media on electronic word of mouth. The key difference between the study conducted by Chu and Kim and this study is that Chu and Kim's study focuses on the encroachment of electronic word of mouth into social media websites. This study, in contrast, will study the incorporation of social media attributes into a restaurant review website. 


\section{WHAT IS THERE TO YELP ABOUT?}

\section{METHODOLOGY}

To execute this study, a discourse analysis was conducted. Discourse analysis may focus on language, themes, grammar, power structures, or linguistic devices (Gee, 2011). It can be top-down, or bottom-up. Top-down discourse analysis involves the researcher beginning from an understanding of the contextual background in which the discourse is taking place and is often a more structured study (Woods, 2006). Alternately, a bottom-up approach to discourse analysis begins with the language being used within the discourse and tends to involve a less structured process (Woods, 2006). As this study was oriented with the particular genre of online restaurant reviews, and looked specifically for linguistic patterns that are applicable to Relevance Theory and the Co-operative Principle, it was considered a top-down discourse analysis.

Due to the inherent flexibility of discourse analyses, the majority of texts draw attention to the lack of protocol, and wide ranging orientations a researcher can take when applying discourse analysis to their text. Gee (2011), for example, describes a wide ranging set of tools that belong to discourse analysis. He goes on to state that none of these tools are superior to others, simply more applicable to different research statements (Gee, 2011). As such, he argues that he is presenting one of many sets of tools that can be applied by researchers when they attempt to conduct their own discourse analysis. Gee's first book being discussed, published in 2005, walks the reader through a variety of examples of discourse analysis conducted on texts he studied throughout his career. In this book, the focus is on seven "building tasks," or arenas, that are used to build language. It goes on to describe a variety of tools of inquiry and situated meaning models (Gee, 2005). In his later book (2011), Gee walks the reader through a much more detailed twenty-seven tools of discourse analysis, illustrated below in Figure 3. 
WHAT IS THERE TO YELP ABOUT?

\begin{tabular}{|l|l|}
\hline Tool \#1: The Deixis Tool & Tool \#15: The Activities Building Tool \\
\hline Tool \#2: The Fill In Tool & Tool \#16: The Identities Building Tool \\
\hline Tool \#3: The Making Strange Tool & Tool \#17: The Relationships Building Tool \\
\hline Tool \#4: The Subject Tool & Tool \#18: The Politics Building Tool \\
\hline Tool \#5: The Intonation Tool & Tool \#19: The Connections Building Tool \\
\hline Tool \#6: The Frame Problem Tool & Tool \#20: The Cohesion Tool \\
\hline Tool \#7: The Doing and Not Just Saying Tool & $\begin{array}{l}\text { Tool \#21: The Signs Systems and Knowledge } \\
\text { Building Tool }\end{array}$ \\
\hline Tool \#8: The Vocabulary Tool & $\begin{array}{l}\text { Tool \#22: The Topic Flow or Topic Chaining } \\
\text { Tool }\end{array}$ \\
\hline $\begin{array}{l}\text { Tool \#9: The Why This Way and Not That } \\
\text { Way Tool }\end{array}$ & Tool \#23: The Situated Meaning Tool \\
\hline Tool \#10: The Integration Tool & Tool \#24: The Social Languages Tool \\
\hline Tool \#11: The Topics and Themes Tool & Tool \#25: The Intertextuality Tool \\
\hline Tool \#12: The Stanza Tool & Tool \#26: The Figured Worlds Tool \\
\hline Tool \#13: The Context is Reflexive Tool & Tool \#27: The Big “D” Discourse Tool \\
\hline Tool \#14: The Significance Building Tool & \\
\hline
\end{tabular}

Figure 3. Gee's Discourse Analysis Tools (Gee, 2011)

These tools can be used in full or part, depending on their applicability, by those conducting a discourse analysis. Ultimately, they are a list of questions that may be asked of the text. Though these tools are not meant to be used as an official handbook as to how to design a discourse analysis methodology, they do provide a context with which to approach a text. The tools incorporated into this study are "The Fill in Tool," "The Doing and Not Saying Tool," "The Stanza Tool," “The Identities Building Tool," and "The Relationship Building Tool."

Some of Gee's tools proved particularly useful when analyzing the restaurant reviews. These tools allowed the analysis to hone in on the particular intricacies of these texts. The first of Gee's tools that has particular applicability with this study is "The Fill in Tool," listed as his second tool. This tool is used to determine what is left unsaid in a text. It describes what must be articulated for the message to become clear, or what is being left out intentionally without 


\section{WHAT IS THERE TO YELP ABOUT?}

affecting the clarity of the messaging, causing the listener to infer the meaning (Gee, 2011). This tool is highly compatible with this study's theoretical orientation of Relevance Theory. If information is left out intentionally without altering clarity, it decreases the processing effort as there is less to read, increasing relevance. If information is left out that is useful, the context will be less applicable, decreasing relevance.

Gee's tool number seven may also have applicability with this study. This is labelled "The Doing and Not Just Saying Tool" and is described as identifying not only what the speaker (or writer) is saying, but what they are trying to accomplish (Gee, 2011). Though the goal of the reviews is ultimately to inform and persuade, many reviewers take on secondary goals within their reviews. These may be to entertain, shock, or increase the reviewer's online presence. As such, these secondary goals will be considered in accordance with any affect they may have on linguistic devices utilized by the reviewers. These may alter the context of the review, adding information that is not necessarily relevant to the persuasiveness, but impacts the readability of the review. This would be considered a different contextual technique with different directed goals.

Gee's tool number twelve, “The Stanza Tool” focuses on the stanza clustering of information. The term stanza is particularly appropriate for Gee as it is applicable to both spoken and written text (2011). As this study focuses solely on written forms of text, this tool drew attention to the formatting of the text, and how it is broken into different sections. The use of headings and bullets in particular were observed, particularly how this affected the clarity of the reviews. The use of heading and bullets may affect the clarity of the review as it will allow readers to retrieve information more efficiently, lowering processing efforts and therefore increasing the relevance of the review. 


\section{WHAT IS THERE TO YELP ABOUT?}

Gee's tools sixteen and seventeen, "The Identities Building Tool” and "The Relationship Building Tool" respectively, also have strong levels of relevance with this study (Gee, 2011). These tools question what grammatical devices are being used by the author in order to establish identities and build relationships. An example of relationship building would be the use of acronyms, which help to create an in-group and an out-group in the restaurant reviews (Woods, 2006). An acronym which occurs frequently in restaurant reviews is AYCE, which stands for "all you can eat." Acronyms such as AYCE serve to decrease the retrieval efforts for those in the 'in-group' who are familiar with their usage, but increase the retrieval efforts for those in the 'out-group' who are unfamiliar with what they stand for. As such, these acronyms serve to impact processing effects as well as impact the maxim of relation, positively or negatively, depending on whether the reader is considered to be a member of the 'in-group' or 'out-group'.

Many of these tools were used when creating the framework with which this methodology was designed. Certain tools, such as "The Relationship Building Tool" and "The Fill-in Tool" influenced the methodology more heavily than others. Other tools, such as "The Stanza Tool" were used when approaching the texts, but ultimately not included in the final analysis.

Relying on a framework designed utilizing Sperber and Wilsons Relevance Theory and Grice's Cooperative Principle, two types of data analysis were conducted on the data set collected. These consisted of a qualitative study of the restaurant reviews, in order to analyse the reviews from a holistic perspective that identified any persuasive linguistic techniques using aspects of both pragmatics and discourse analysis. Relevance Theory and the Co-operative Principle were used to foreground the discourse analysis and determine the linguistic devices which would be searched for within the restaurant reviews. 


\section{WHAT IS THERE TO YELP ABOUT?}

Online restaurant reviews from non-professional reviewers meet the maxims within the Co-operative Principle and the principles of Relevance Theory for a variety of reasons, particularly those on the website Yelp. Primarily, these reviews are designed to inform and persuade, already allowing them to reflect the maxims of the Co-operative Principle. However, due to the high volume of information available on the internet, these reviews must also have the highest level of relevancy in contrast to other reviews to be deemed a superior review, and as such be garnered attention. Reviews that have lower levels of relevancy will quickly fall into disfavour and be disregarded and unused, thereby increasing the importance of ensuring a review is of maximum relevancy for its readers.

Both the Cooperative Principle and Relevance Theory were applied when designing the discourse analysis. Each of Grice's principles as well as the two principles of relevance were incorporated into the study's design to ensure the reviews were attaining maximum relevancy. The discourse analysis served to identify three linguistic devices (each with subsections) within the restaurant reviews: adjectives, personal pronouns, and credibility statements. The study of adjectives embedded within the restaurant reviews allowed for an analysis into the maxim of quality and manner, as they provided information as to the level of detail provided by the restaurant review. The study of personal pronouns allowed for information to be retrieved regarding the maxim of both quality and relation, as second-person personal pronouns could be used to establish relationships as well as provide information that was maximally relevant to the user. The study of credibility statements was used to determine the maxim of relation as it determined the credibility of the author, and as such the credibility of each statement. Further, word counts were tracked to determine the maxim of quantity, in order to determine an optimal level of information shared in a successful restaurant review. 


\section{WHAT IS THERE TO YELP ABOUT?}

Further, this study incorporates both the processing effects and positive cognitive effects of Relevance Theory. It was anticipated that the incorporation of descriptive adjectives and first and second-person personal pronouns would provide positive cognitive effects while decreasing processing efforts. The use of credibility statements, a concise review, and second-person personal pronouns were hypothesized to increase the positive cognitive effects, providing the maximum level of information framed in any easy-to-retrieve method without cluttering the review with extraneous details.

As such, the study was set up to identify the instances of these three linguistic devices, broken down into nine subsections in total. The definitions used for each of these terms are as follows:

1. Descriptive Adjectives: Words used to define or modify nouns or pronouns; a basic form of adjective that provides concrete, useful, and informative supporting details. These may fall into the categories of color, size, quality, or time to name a few examples. Adjectives that were attached to the official names of dishes (i.e., "orange chicken") were excluded. Descriptive adjectives provide strong supporting details of the reviewer's experience or the food quality. Examples of descriptive adjectives are "neon color of the chicken" and "this portion is large enough to feed two."

2. Indefinite Adjectives: Words used to define or modify nouns or pronouns; adjectives that are vague and do not point to anything specific. These adjectives provide little to no supporting detail to the reader. An example is "there were several options on the menu."

3. First-Person Personal Pronouns: Personal pronouns can be singular or plural, male, female, or gender neutral, and refer to specific persons or things. Personal pronouns 


\section{WHAT IS THERE TO YELP ABOUT?}

function as noun equivalents, and may exist in first, second, or third-person. An example of a first-person personal pronoun is "I" or "me," and these terms are used when referring to oneself.

4. Second-Person Personal Pronouns: An example of a second-person personal pronoun is "you." Second-person personal pronouns are used when referring to the reader.

5. Third-Person Personal Pronouns: An example of a third-person personal pronoun is "she" or "it" and these terms are used when referring to something/someone separate from the reader or writer.

6. Indirect Credibility Statement: Credibility statements are phrases in which the author expresses some form of authority on the subject matter. These statements do not have to be direct claims, and are often embedded indirectly into reviews in forms such as descriptions of reviews previously posted, or restaurants frequently visited. Any statements discussing previous reviews or knowledge regarding other restaurants will be considered indirect credibility statements. An example of an indirect credibility statement is, "The food was not as good as at the restaurant down the street."

7. Direct Credibility Statement: Statements referring to Yelp Elite status, or directly stating credibility or a familiarity with a genre of food will be considered direct credibility statements. An example of a direct credibility statement is, "I know a lot about Chinese food; since I grew up eating it."

8. Direct Non-Credibility Statement: Non-credibility statements will be considered statements that reference the reviewer's lack of knowledge or confidence in their review. Statements that reflect a lack of authority on the topic will be considered 


\section{WHAT IS THERE TO YELP ABOUT?}

indirect non-credibility statements. Statements such as "I don't know" or "you decide" will be considered direct non-credibility-statements.

9. Indirect Non-Credibility Statement: Indirect non-credibility statements will be considered statements that subtly imply a user is not confident in their review, particularly through referencing their lack of familiarity with a genre of food or particular restaurant. "This was my first time eating Thai food" is an example of indirect-non-credibility statements.

The data set collected consisted of fifty reviews, ranging in length from 9 words to 653 words. This sample was composed of five reviews for each star rating (1-5) from Non-Elite reviewers and five reviews for each star rating from Elite member reviewers for a total of fifty reviews. The first reviews that met each category from the "recent Toronto restaurant reviews" tab on the Yelp website were taken into this sample. Due to the frequency that reviews are posted, the majority came from the same four-day period. As reviews are continually being added to the website, the context of this genre is continually shifting as new reviews are added, allowing both the genre and content to continually evolve. The reviews were collected on May $10^{\text {th }} 2011$, in the late afternoon, with the exception of two Elite reviews in both the one and five star category. Due to the rarity of these reviews, a small portion of reviews from these categories were collected from subsequent days to complete the sample. Screenshots of each review were captured, saved, and then information was transferred to a word document. The word document identified the date, restaurant, reviewer, word count, and review text. These documents were stored in both electronic and print copies. 


\section{WHAT IS THERE TO YELP ABOUT?}

The discourse analysis of these reviews was conducted on the electronic copy. Separate word documents were created for each category: adjectives, credibility statements, and personal pronouns. The Microsoft word highlight tool was then used to identify instances of each subsection of these devices, using a color coding system illustrated on the top of each document, with a maximum of three colour symbols per document. Three documents were utilized for a variety of reasons. Primarily, as each term could fall into more than one linguistic category, this prevented confusion in the case of overlap. Further, this allowed the color-coding system to remain simple, with a maximum of three colors per page, and allowed for clarity when reviewing the documents. Lastly, this allowed for a visual representation of the findings, which provided an intuitive interpretation of the findings before the data was officially counted and analysed. Each document was reviewed three times to ensure precision of data coding. All data was coded by one researcher, and no computer programming was utilized due to the introductory scope of this project. 


\section{Analysis \& Interpretation}

A chart, identifying each term and review category, was used to track the findings. This chart can be seen as Figure 4. Average word counts of each category were contrasted, illustrated in Figure 5.

\begin{tabular}{|c|c|c|c|c|c|c|c|c|c|c|c|c|}
\hline & $\begin{array}{l}\text { Elite } \\
\text { (1 star) }\end{array}$ & $\begin{array}{l}\text { Non- } \\
\text { Elite } \\
\text { (1 star) }\end{array}$ & $\begin{array}{l}\text { Elite } \\
\text { (2 star) }\end{array}$ & $\begin{array}{l}\text { Non- } \\
\text { Elite (2 } \\
\text { star) }\end{array}$ & $\begin{array}{l}\text { Elite } \\
\text { (3 star) }\end{array}$ & $\begin{array}{l}\text { Non- } \\
\text { Elite } \\
(3 \mathrm{star})\end{array}$ & $\begin{array}{l}\text { Elite } \\
\text { (4 star) }\end{array}$ & $\begin{array}{l}\text { Non- } \\
\text { Elite } \\
\text { (4 star) }\end{array}$ & $\begin{array}{l}\text { Elite } \\
(5 \\
\text { star })\end{array}$ & $\begin{array}{l}\text { Non- } \\
\text { Elite } \\
(5 \\
\text { star })\end{array}$ & Elite & $\begin{array}{l}\text { Non- } \\
\text { Elite }\end{array}$ \\
\hline $\begin{array}{l}\text { Descriptive } \\
\text { Adjective }\end{array}$ & 27 & 28 & 21 & 47 & 102 & 28 & 76 & 42 & 84 & 16 & 310 & 161 \\
\hline $\begin{array}{l}\text { Indefinite } \\
\text { Adjective }\end{array}$ & 23 & 23 & 23 & 33 & 45 & 37 & 42 & 37 & 29 & 18 & 162 & 148 \\
\hline $\begin{array}{l}\text { First-person } \\
\text { pronoun }\end{array}$ & 37 & 28 & 27 & 49 & 34 & 25 & 32 & 43 & 45 & 14 & 175 & 159 \\
\hline $\begin{array}{l}\text { Second- } \\
\text { person } \\
\text { pronoun }\end{array}$ & 14 & 1 & 4 & 1 & 8 & 2 & 9 & 4 & 11 & 1 & 46 & 9 \\
\hline $\begin{array}{l}\text { Third- } \\
\text { person } \\
\text { pronoun }\end{array}$ & 31 & 16 & 15 & 28 & 49 & 10 & 23 & 15 & 32 & 9 & 150 & 78 \\
\hline $\begin{array}{l}\text { Direct } \\
\text { Credibility } \\
\text { Statement }\end{array}$ & 2 & 0 & 1 & 3 & 0 & 1 & 0 & 1 & 0 & 2 & 3 & 7 \\
\hline $\begin{array}{l}\text { Indirect } \\
\text { Credibility } \\
\text { Statement }\end{array}$ & 8 & 1 & 8 & 2 & 16 & 1 & 7 & 5 & 1 & 2 & 40 & 11 \\
\hline $\begin{array}{l}\text { Direct Non- } \\
\text { Credibility } \\
\text { Statement }\end{array}$ & 1 & 0 & 0 & 0 & 1 & 0 & 0 & 0 & 2 & 0 & 4 & 0 \\
\hline $\begin{array}{l}\text { Indirect } \\
\text { Non- } \\
\text { Credibility } \\
\text { Statement }\end{array}$ & 0 & 0 & 1 & 1 & 0 & 0 & 4 & 2 & 3 & 0 & 8 & 3 \\
\hline
\end{tabular}

Figure 4. Illustration of Elite and Non Elite Review Findings of Linguistic Devices 
WHAT IS THERE TO YELP ABOUT?

\begin{tabular}{|l|l|l|l|l|l|l|}
\hline & 1 & 2 & 3 & 4 & 5 & Average \\
\hline Elite & 162.6 & 113.6 & 337 & 189 & 243.4 & 209.1 \\
\hline Non-Elite & 108.8 & 213.4 & 130 & 168.2 & 78.6 & 139.8 \\
\hline & 53.8 & -99.8 & 207 & 20.8 & 164.8 & 69.3 \\
\hline
\end{tabular}

Figure 5. Illustration of Elite and Non-Elite Word Count

All five of the star ratings were utilized and separated as it is likely that the star rating, which is representative of the user experience, may strongly influence the language used by reviewers as well as tone and length of the review. Reviewers who had extremely positive or negative experiences were likely to use different language or descriptive techniques that would alter each review considerably. As such, reviews from all star ratings were analyzed and contrasted to ensure that the comparison between Elite and Non-Elite member reviews were on comparable levels of satisfaction with the restaurants. For this reason, Figure 4 directly compared reviews across star ratings (i.e., one-star Non-Elite reviews and one-star Elite reviews) to ensure consistency of data. Due to this method of comparison, it was anticipated that trends might appear regarding linguistic devices utilized across different star ratings as well as the different linguistic devices utilized by Elite and Non-Elite reviewers. Though the ultimate goal was to identify trends differing between Elite and Non-Elite reviewers, it was imperative to track the star rating to ensure that this was not a prime factor affecting the linguistic devices utilized.

Five reviews of each star rating and reviewer type were used to ensure that an accurate representation of the data set was achieved. This quantity should ensure that outliers do not strongly alter the data collected while still providing a manageable quantity of reviews for a project of this scope. When determining word count, outliers, or reviews with word counts that were significantly longer or shorter than the average word count, were not eliminated from the data set. After viewing the broad ranging word counts, it became evident that the length of the reviews was a relatively consistent representation of each reviewer's personal writing style. As 


\section{WHAT IS THERE TO YELP ABOUT?}

the maxim of quantity is one of the four maxims' being interpreted, the length of each review was deemed to be the most effective measure of this maxim. Elimination of any reviews based on length would significantly alter the information provided regarding quantity of information provided.

Upon completing the discourse analysis, identifying differences in the quantity of the nine linguistic terms within Elite and Non-Elite reviewers, it became evident that there were notable differences within seven of nine categories of linguistic devices. Further, notable differences were found within the word count of Elite and Non-Elite reviewers, with this trend being consistent in all but one of the star rating levels. Many of the original hypotheses were confirmed, and ultimately conclusive differences between Elite reviews and Non-Elite reviews were identified.

Descriptive adjectives were the first linguistic device identified within this discourse analysis. Descriptive adjectives were considered adjectives that provided concrete information about a noun. There were significant differences within the level of descriptive adjectives utilized between the two review categories, with Elite reviewers using almost double the quantity of descriptive adjectives in contrast with Non-Elite reviewers. Within the twenty-five reviews, 361 instances of descriptive adjectives were found within Elite reviews. Within the data set of twenty-five Non-Elite reviews, 161 instances of descriptive adjectives were identified. Adjectives attributed to the name of a restaurant dish were excluded, and as such the number would have been significantly higher if these were included in the study. However, these adjectives were considered a dish name rather than supporting detail, and as such not included within the category of descriptive adjective. Descriptive adjectives were identified as having a strong association with Grice's maxim of quality. The more finite the information provided with 


\section{WHAT IS THERE TO YELP ABOUT?}

these descriptive adjectives, the more likely the information was to be of high quality. Further, descriptive adjectives are highly associated with Sperber and Wilson's concept of contextual effects; as increasingly descriptive adjectives provide richer information to the user.

It seems logical to follow that Elite Reviews had an increased level of descriptive adjective usage. As the ultimate goal of an online restaurant review is to inform and persuade, the prevalence of these adjectives even in Non-Elite reviews is logical, as providing richer information aids in the persuasion process. As such, both types of reviews appear to support the conclusion that descriptive adjectives are of the utmost importance within restaurant reviews. This linguistic device provides the users with tangible information they can use when making their decisions, and are clearly identified as being of maximum importance in the creation of a successful persuasive restaurant review.

The next linguistic device identified was the use of indefinite adjectives. These terms were often vague; the most frequently used being "good" and "great". According to the maxim of quality, these linguistic devices provide low levels of information. These terms added low contextual effects, as they did not provide highly useful information that added to or contradicted previously existing information. These terms did not, however, make the reviews more difficult to read, or increase the processing effort. For these reasons, it was anticipated that these terms would appear with a similar frequency between Elite and Non-Elite reviews. The data identified 162 instances of indefinite adjectives within the twenty-five Elite reviews, and 148 instances of indefinite adjectives within the twenty-five Non-Elite reviews.

Though these linguistic devices provide low levels of information, they are also short terms that do not increase the length to the point that they increase the processing effort. As it 


\section{WHAT IS THERE TO YELP ABOUT?}

appears that indefinite adjectives are heavily utilized in restaurant reviews, it is likely that their incorporation into these reviews should not be entirely removed. Rather, the results of this study indicate that an effective review would substitute indefinite adjectives with descriptive adjectives in instances where it is applicable, and maintain the use of indefinite adjectives in other instances. Though entrenched within the restaurant review, indefinite adjectives appear to have little sway on the persuasiveness of an online restaurant review.

First-person personal pronouns were the next linguistic device identified. These terms were often used to set the scene or provide a more personal approach to the restaurant review. As "personal pizzaz" was identified by the administrators of Yelp as a positive aspect of these reviews, it could be hypothesized that Elite reviews would have significantly higher levels of first-person personal pronouns within their reviews. However, the maxim of relation is the only maxim that these terms could logically serve to strengthen. Using this logic, directly identifying the user of the review, using second-person personal pronouns, would appear to be a stronger method of engaging the user. Further, as these reviews reflect each reviewer's own personal experience, they are very likely to all incorporate high levels of first-person personal pronouns. For these reasons, it is logical that Elite and Non-Elite reviews would have similar levels of firstperson personal pronouns. Within both Elite and Non-Elite reviews, this was the most predominant type of pronoun utilized. Elite reviews illustrated 175 instances of first-person personal pronouns, whereas Non-Elite reviews utilized 159 instances of first-person personal pronouns.

These results point towards the frequency with which first-person personal pronouns are entrenched within the online restaurant review genre. It appears that with the frequency they appear, these terms are likely necessary in order to create an effective restaurant review. 


\section{WHAT IS THERE TO YELP ABOUT?}

However, due to the low level of discrepancy between Elite and Non-Elite reviews, it is unlikely that the high use of first-person personal pronouns increases the persuasiveness of these reviews or serves to set reviewers apart.

Second-person personal pronouns are the next linguistic device studied. These terms originally sparked the concept of a linguistic analysis, as it was estimated that they would increase the level of relevance of each review significantly. These terms were anticipated to be highly applicable to the maxim of relation, as they served to establish a relationship with the user by engaging them in the review. Further, they were anticipated to increase contextual effects by framing the information as pertinent to the user. These terms were also anticipated to decrease the processing effects, as they explicitly spelled out how this information was relevant to the user. The data unequivocally supported the initial hypothesis that Elite reviews would feature higher levels of second-person personal pronouns. Elite reviews featured 46 instances of secondperson personal pronouns, whereas Non-Elite reviews featured only 9 instances of second-person personal pronouns.

As Elite reviews utilize over five times the quantity of second-person personal pronouns when compared to Non-Elite reviewers, it becomes evident that these linguistic devices are highly useful when creating a review that is persuasive and maximally relevant. Further, the lower levels of second-person personal pronouns when contrasted with first-person personal pronouns points towards the likelihood that incorporating these terms into a review would set that review, and therefore reviewer, apart significantly. The large discrepancy between Elite and Non-Elite reviewers' usage of second-person personal pronouns points towards the importance of incorporating higher quantities of these terms into reviews in order to increase the level of 


\section{WHAT IS THERE TO YELP ABOUT?}

persuasiveness. This likely illustrates the use of second-person personal pronouns to draw the reader in and establish a sense of community.

The next linguistic term identified was third-person personal pronouns. Though too heavy a reliance on these terms might result in a vague and difficult to follow review (increasing processing effects), they can also be utilized effectively when the writer is aiming to provide levels of supporting detail without becoming repetitive (aiding in the maxim of quality). For this reason, it was anticipated that there would be minimal differences between Elite and Non-Elite reviewers usage of third-person personal pronouns. The results of the discourse analysis indicated that there were 150 instances of third-person personal pronouns within Elite reviews, and only 78 instances within Non-Elite reviews.

These results support the concept that, when the term they are referring to is clearly identifiable, third-person personal pronouns can be efficient linguistic devices to incorporate into restaurant reviews. They allow the user to provide extensive additional details, increasing the maxim of quality, without artificially lengthening the review, supporting the maxim of quantity. In cases where it is clearly articulated what object these third-person personal pronouns are referring to, processing efforts are likely to be decreased. Results of this study indicate that, when used properly, third-person personal pronouns can be utilized as effective linguistic devices to incorporate into restaurant reviews. Though these devices on their own are unlikely to directly alter the effectiveness of the review, they serve as tools that allow the reviewer to provide valuable information in a concise manner rather than repeating the noun being referred to, thereby creating a more persuasive review. 


\section{WHAT IS THERE TO YELP ABOUT?}

Credibility statements were the next linguistic device utilized, and they were broken down into four distinct categories: Direct credibility statements, indirect credibility statements, direct non-credibility statements, and indirect non-credibility statements. Direct Credibility statements were originally assumed to be an excellent indicator of persuasiveness, as they would establish an air of authority on the subject matter, increasing perceived quality of reviews, as information would be perceived as more credible by the reader. Further, the increased credibility would alter the maxim of relation, creating a power dynamic between the two individuals that made the reader want to listen to the advice of the reviewer. However, in the absence of additional review characteristics or the official title of Elite reviewer, the use of direct credibility statements could be viewed as over-compensatory. Further, the Elite reviewers have an innate credibility statement embedded within each of their reviews in the form of their Elite status badges. The discourse analysis identified only three instances of direct credibility statements within Elite reviews, whereas it identified seven instances of direct credibility statements within Non-Elite reviews.

There are a variety of possible explanations for the low levels of direct credibility statements within Elite restaurant reviews, including the strong likelihood that the Elite badge actually serves as a direct credibility statement. The higher levels of credibility statements amongst the Non-Elite reviewers draws attention to the likelihood that Non-Elite reviewers who still have to prove their credibility are more likely to incorporate these statements into their reviews. For these reasons, it is likely that non-established reviewers will gain more from incorporating credibility statements into their reviews than more established reviewers.

Indirect credibility statements differ slightly from direct credibility statements. These are generally instances where the author refers to other reviews posted or restaurants visited. These 


\section{WHAT IS THERE TO YELP ABOUT?}

statements are likely to increase the maxim of quality (providing information on neighbouring restaurants), which would have a high contextual effect as it would provide relevant information on not only the restaurant in question, but other nearby restaurants the user might consider. Further, these statements would serve to increase the maxim of quality in making information seem more credible and providing information regarding multiple restaurants, as well as the maxim of relation by increasing the credibility of the author. As these are indirect credibility statements, the writer has less motivation to use them as compensatory statements. Results of the discourse analysis identified 40 instances of indirect credibility statements within Elite reviews, and eleven instances of indirect credibility statements within Non-Elite reviews.

These results indicate that Elite reviewers are more likely to incorporate indirect credibility statements into their reviews. This may be for a variety of reasons. These reviewers may be more likely to eat at restaurants more frequently, allowing them to have higher quantities of experiences to draw upon. They may also be likely to have written a greater number of reviews that they can reference. Further, as the Elite badge serves as a form of a direct credibility statement, these users may be using indirect credibility to reinforce this air of authority. Overall, the high incidences of indirect credibility statements embedded within these reviews draws attention to the fact that they are very likely an effective tool, to both add information and establish credibility, increasing both the maxim of relation and the maxim of quality.

The next linguistic device studied within these reviews was the use of direct noncredibility statements. Results indicated that there were four instances of direct non-credibility statements within Elite member reviews, and zero instances within Non-Elite member reviews. Direct non-credibility statements were seen as unlikely to add information that was relevant for 


\section{WHAT IS THERE TO YELP ABOUT?}

the user; therefore they were anticipated to have low contextual effects. Further, these statements lengthened reviews without providing information that the user could utilize; therefore they were seen as likely to poorly impact the maxim of quantity. When these comments did appear, they were often referencing that it was the writer's first time visiting that establishment. It could be argued that these statements were embedded within the reviews to add narrative details, adding personal details to the review.

Though the use of direct non-credibility statements occurs only within Elite member reviews, low instances of these comments exist. These comments are generally included within reviews to reference that it is the writers first time at a restaurant, which may be embedded to protect the writer's credibility within the website. As such, it may be assumed that these hedging terms do not add value to the review, but do help to safeguard the reviewer's status if they are unsure that their experience at a restaurant is representative. This is particularly helpful for Elite users, who have created a reputation for themselves they feel the need to protect.

The last linguistic device sought within the reviews was the use of indirect noncredibility statements. These statements are similar in function to the direct non-credibility statements. Indirect non-credibility statements are assumed to add length to a review, negatively impacting the maxim of quantity. Further, they de-value the information provided, negatively impacting the maxim of quality. The contextual effect of the indirect non-credibility statement in itself will be high, as it will be providing the user with relevant information regarding the authority of the reviewer. However, these statements negatively impact the overall contextual effect of the entire review, limiting the credibility. Given this information, it can be assumed that though it may seem counter-intuitive, indirect non-credibility statements again serve to hedge a user's online reputation rather than strengthen the persuasiveness of a review. 


\section{WHAT IS THERE TO YELP ABOUT?}

Analysis of the fifty restaurant reviews identified four instances of indirect noncredibility statements within Elite member reviews and zero instances of indirect non-credibility statements within Non-Elite member reviews. Following the precedent set by the direct noncredibility statements, this pattern supports the premise that non-credibility statements, both direct and indirect, serve as hedging terms to protect the reputation of reviewers. As Elite reviewers have developed a stronger reputation, they have higher incentives to protect these reputations by utilizing these hedging terms. However, the individual review's persuasiveness may suffer through the incorporation of these linguistic devices. As such, it becomes clear that each reviewer's reputation may take precedence over the individual review's persuasiveness as a reviewer priority.

The last aspect of the restaurant reviews that was compared was the word count of Elite versus Non-Elite reviews, seen above in Figure 4. The original intent when studying word count was to adjust for outliers, as the reviews range from nine words to six hundred and fifty three words. However, it quickly became evident that there was no scale for "outliers". A significant portion of both Elite and Non-Elite reviews fell well under fifty words, and well over threehundred and fifty words. Further, it quickly became clear that the length of each review was highly indicative of each individual reviewer's style. As the maxim of quantity is being considered a critical measure into the effectiveness of each review, it was deemed necessary that each review be included in the averages, and no review be excluded for its "outlier" status.

When reading this sample of restaurant reviews, it became clear that the length would be considered an important review attribute. Ultimately, a review's length affects many other maxims. A review that is far too short will likely have a negative impact on the maxim of quality, as it will negatively impact the level of information provided. A review that is far too 


\section{WHAT IS THERE TO YELP ABOUT?}

long will have a negative impact on the processing effort, as it will require the reader to sift through erroneous information. However, the maxim of quantity is the most accurate representation of the impact of a review length on the review's persuasiveness.

The average review length varied significantly, both amongst Elite and Non-Elite reviews and amongst the star ratings. However, in all but one of the star rating categories, it was found that the Elite reviews had a higher word count. The average word count of an Elite review was found to be 209.1 words, while the average word count of a Non-Elite review was found to be 139.8 words. These leads to an average of 69.3 more words per Elite review. With the exception of the two-star reviews, in which the Non-Elite reviews have a higher average word count by 99.8 words, each star rating illustrates an average in which the Elite reviews have a word count that is a minimum of 20.8 terms higher, and a maximum of 164.8 terms higher than the Non-Elite reviewers.

Though it is clear that word count can positively or negatively impact a review, it appears that Non-Elite reviewers are erring on the side of brevity to the point that it is negatively impacting their reviews. The wide-range of review lengths makes it clear that each reviewer adopts their own personal style, which is often heavily reflected in their average word count. As such, though it is clear that the average Elite reviewer provides a slightly longer review, there is likely no ideal review length to emulate in order to write an optimally persuasive review.

The discourse analysis revealed two very different types of reviews, as illustrated in Figure 6. An average Elite member review will be 209 words long. It will contain approximately 12.4 descriptive adjectives and 6.5 indefinite adjectives. It will also contain 7.0 first-person personal pronouns, 1.8 second-person personal pronouns, and 6.0 third-person 


\section{WHAT IS THERE TO YELP ABOUT?}

personal pronouns. It will contain only 0.1 direct credibility statements, 1.6 indirect credibility statements, 0.2 direct non-credibility statements, and 0.3 indirect non-credibility statements. In other terms, only twelve of every hundred Elite reviews contain direct credibility statements, sixteen would contain direct non-credibility statements, and thirty-two would contain indirect non-credibility statements.

An average Non-Elite member review would illustrate significant variations. This review would be 139.8 words, significantly shorter than its Elite counterpart. It would contain only 6.4 descriptive adjectives, almost half of the quantity illustrated in the average Elite member review. It would also contain 5.9 indefinite adjectives, slightly fewer than the 6.5 indefinite adjectives contained within the Elite review. This review would contain 6.4 first-person personal pronouns, only slightly fewer than the Elite review's 7.0 first-person personal pronouns. It would, however, only contain 0.4 second-person personal pronouns (or 36 of every 100 Non-Elite reviews contain one second-person personal pronoun). This is a significant reduction from the 1.8 second-person personal pronouns that would be embedded within each average Elite review. It would also contain 3.1 third-person personal pronouns in contrast to the Elite review's 6.0 third-person personal pronouns. This review would contain a higher level of direct credibility statements, at 0.3 direct credibility statements in contrast to 0.1 (or 28 of 100 as opposed to 12). It would contain fewer indirect credibility statements, 0.4 in stark contrast to the 1.6 embedded within the average Elite member review. It would contain zero direct non-credibility statements in contrast to the Elite member's 0.2 direct non-credibility statements. It would also contain 0.1 indirect non-credibility statements, or 12 out of 100 reviews would contain indirect noncredibility statements. This is significantly fewer than the 32 of 100 Elite reviews that would contain indirect non-credibility statements. 
WHAT IS THERE TO YELP ABOUT?

\begin{tabular}{|l|l|l|}
\hline & Elite & Non-Elite \\
\hline Word Count & 209 & 139.8 \\
\hline Descriptive Adjectives & 12.4 & 6.4 \\
\hline Indefinite Adjectives & 6.5 & 5.9 \\
\hline First-Person Personal Pronouns & 7.0 & 6.4 \\
\hline $\begin{array}{l}\text { Second-Person Personal } \\
\text { Pronouns }\end{array}$ & 1.8 & 0.4 \\
\hline Third-Person Personal Pronouns & 6.0 & 3.1 \\
\hline Direct Credibility Statements & 0.1 & 0.3 \\
\hline Indirect Credibility Statements & 1.6 & 0.4 \\
\hline $\begin{array}{l}\text { Direct Non-Credibility } \\
\text { Statements }\end{array}$ & 0.2 & 0.0 \\
\hline $\begin{array}{l}\text { Indirect Non-Credibility } \\
\text { Statements }\end{array}$ & 0.3 & 0.1 \\
\hline
\end{tabular}

Figure 6. Average Elite and Non-Elite Review

As can be viewed, there are areas in which the Elite and Non-Elite reviews differ significantly. Based on these findings, it can be assumed that the maxims associated with Grice's Co-operative Principle (the maxim of quality, the maxim of quantity, the maxim or relation, and the maxim of manner) have differing levels of importance in regard to online restaurant reviews. Further, Sperber and Wilson's Relevance Theory proved to provide a strong framework upon which to design the discourse analysis for online restaurant reviews. This framework has illustrated that concrete differences exist between Elite and Non-Elite reviews. 


\section{WHAT IS THERE TO YELP ABOUT?}

\section{Conclusion}

The original research question asked was: What can the tools of discourse analysis tell us about the evolution of the genre of restaurant reviews as it moves into an online and usergenerated context? As the findings of this study illustrate, there are concrete review characteristics that are valued on Yelp, reflecting changes in the genre of online restaurant reviews. Those characteristics that appear to be the most highly valued are a high usage of descriptive adjectives, both second and third-person personal pronouns, and indirect credibility statements, as well as a slightly longer word count. Characteristics that appear to be valued, but at a lower level, are an increase in indefinite adjectives, first-person personal pronouns, and the use of indirect and direct non-credibility statements when required in order to protect the reviewer's reputation.

In applying Relevance Theory and Grice's Co-operative Principle, it becomes evident that the characteristics most highly valued are those that increase the maxim of quality while appropriately balancing the maxim of quantity. For this reason, descriptive adjectives, which are generally equal in length to indefinite adjectives, are more highly valued on Yelp. These adjectives provide richer information and therefore have a stronger impact on the maxim of quality. Further, the ability to decrease processing effects while increasing contextual effects is highly valued amongst these reviews. For this reason, second-person personal pronouns, which directly relate a review to the user, are valued more highly than first-person personal pronouns. This also serves to explain why indefinite adjectives, which would have lower contextual effects, are less valued than descriptive adjectives. 


\section{WHAT IS THERE TO YELP ABOUT?}

This study ultimately contributed in two ways to the academic discussion of restaurant reviews. Primarily, it answered the research question set out in the introduction: What can the tools of discourse analysis tell us about the evolution of the genre of restaurant reviews as it moves into an online and user-generated context? These findings can ideally be applied to a variety of online product reviews throughout North America on a variety of review websites. As such, it serves to identify linguistic devices that are considered persuasive within product reviews. These findings are relevant to a variety of groups, including but not limited to linguists, academics, marketers, business owners, and review writers.

This study is also relevant for those interested in studying Grice's Co-operative Principle and Sperber and Wilson's Relevance Theory. Primarily, it illustrates the ease of which these theories can be combined to create an effective analysis of a text, despite that Relevance Theory was originally based upon the Co-operative Principle and meant to be a more refined and applicable version of this theory. Secondly, this study illustrates the applicability of both of

these theories in an online environment. Both of these theories were written in a largely printbased time period, and as such not originally created for a web based environment. However, as illustrated within this study, both theories are highly applicable in an online environment. In fact, with the ease of access to information and overwhelming quantity of information available online, these theories, Relevance Theory in particular, have likely gained higher levels of applicability. The high correlation between the maxim's and linguistic devices identified within these reviews and the findings of this study clearly illustrate the applicability of both theories to an online environment.

Due to the scope of this project, the results are indicative of the linguistic devices that are valued amongst restaurant reviews written by Toronto reviewers on the website Yelp. This 


\section{WHAT IS THERE TO YELP ABOUT?}

introductory study illustrates the importance of providing information that is contextually rich and requires low processing efforts to retrieve. In online restaurant reviews, it is evident that this information comes largely in the form of descriptive adjectives and second-person personal pronouns. However, this project's small scope is evidenced in its highly descriptive rather than conclusive findings. Rather than as a final answer to the issue of how to communicate online, this study should serve as a launching point. As illustrated by Cheung (2009), it is clear that these findings can only be conclusively applied to Yelp users within the General Toronto Area (GTA) as persuasion styles may differ significantly amongst those of various cultures and regions.

Future research on this subject matter would ideally conduct a discourse analysis that attempted to identify similar findings amongst a wider range of reviews from a more diverse region. Similar linguistic devices could be identified within these reviews in order to determine whether these findings are consistent amongst reviews from a broader region, other review websites, and reviews of other types of products and services.

As illustrated by Cheung (2009), different cultural practices encourage different methods of persuasion. As such, it is highly unlikely that an effective North-American approach to persuasion would be considered equally effective in a region that varies culturally such as China. However, an expansion on this study would likely attempt to identify the scope of these persuasion technique's applicability. A discourse analysis conducted of reviews throughout various Ontario, Canadian, and North American websites may serve as useful to identify the scope of this studies applicability. Due to wide-ranging cultural differences, it is unlikely that the scope of these findings would apply beyond North American borders. Further, Toronto's highly multicultural population may in fact make it a unique region. It is possible that due to 


\section{WHAT IS THERE TO YELP ABOUT?}

high cultural differences even amongst Toronto and other Ontario cities, the scope of these findings will be limited to Toronto and similarly multicultural North American cities. It is also entirely possible that due to the widespread usage of the internet, allowing users from a variety of regions to access similar reviews, these findings could be applicable throughout North America. As such, a discourse analysis of reviews throughout these various regions would be required in order to assess the scope of the applicability of these findings.

Another research limitation of this study is that it is specific to one website, Yelp.ca. Though it is common academic practice to focus on one source of text, as evidenced in Steffes and Burgee's study using the website Rate my Professor (2008) and Cheung's study of direct marketing e-mails (2009), it is necessary to attempt to apply these findings to a variety of online review websites in order to determine the scope of their applicability. As such, further research would be required to conduct a discourse analysis of other restaurant review websites using the same framework identified within this study in order to determine whether these attributes are specific to Yelp. Due to many of the unique characteristics of the Yelp website, it is likely that other review websites may have findings that differ slightly from those identified within Yelp reviews. Most significantly, the use of the Elite badge and personal profiles allows users to establish credibility externally from their reviews. This has led to a decreased need to establish credibility embedded within each review, as evidenced by the low level of direct credibility statements within Elite reviews. Though certain aspects of the reviews, such as the importance of second-person personal pronouns and descriptive adjectives, are unlikely to change significantly on alternate review websites, the usage of credibility statements and establishment of credibility within the reviews would likely alter significantly. As such, it would be interesting to determine both the differences between the reviews on Yelp and other restaurant review 


\section{WHAT IS THERE TO YELP ABOUT?}

websites holistically, and the differences between the approaches to establishing credibility. Further, another study could serve to investigate whether online reviews were considered more persuasive with credibility statements being established internally (as in on traditional review websites) or external to the review (as seen on Yelp). The creation of this form of study would likely require a high quantity of restaurant reviews and interaction with subjects who were interviewed or surveyed upon reading differing reviews in order to gauge persuasiveness, and as such would be quite wide in scope.

A broader study may also provide informative that attempted to identify whether there were different linguistic devices that were considered persuasive amongst other types of online product reviews. As restaurant experiences are generally unique to each individual, perishable, and intangible, it is likely that these reviews may require different approaches in order to be deemed persuasive than other business or product reviews. Traditional product reviews differ in a variety of key regards. Primarily, traditional products are tangible. As such, these products can be described with more finite terms than services can be. The tangibility of these products also allows for an option of returning said product, significantly lowering the risk involved for the consumer. At restaurants, the primary product is food, though the establishment is also selling ambiance, relaxation, entertainment, and an overall experience. As such, though the food can frequently be returned if there is a high level of dissatisfaction, the user's time will be considered wasted and non-refundable. Due to the highly unique aspects of a restaurant experience, it would be interesting and informative to contrast these online reviews with the online reviews of traditional products to identify persuasive differences between the two.

Though only a launching point, the findings of this study may prove highly useful for future researchers. In identifying what review attributes are valued, as evidenced by the Elite 


\section{WHAT IS THERE TO YELP ABOUT?}

reviews on Yelp, this study has identified what linguistic devices increase persuasiveness in online reviews. This has applications to the study of persuasiveness in an online environment. It also allows for insights into the removal of credibility from within a review to an alternate location (the Elite badges and the use of user profiles), a tactic that may be mimicked by a variety of other websites in the future. It also has levels of relevance to marketers, who may be able to apply this information to more effectively manage the reputations of companies they represent online. This information can also be applied by review writers hoping to increase their levels of persuasiveness in order to strengthen their reputations on an online review website such as Yelp, potentially to increase and manage their online presence. Finally, this study has many implications for scholars. It illustrates the applicability of both Relevance Theory and the Cooperative Principle in an online environment. It also serves as a launching point into the linguistic devices that have high levels of persuasiveness amongst restaurant reviews, important information for both the rhetorician and the linguist. 
WHAT IS THERE TO YELP ABOUT?

\section{Works Cited}

Cutting, J. (2008). Pragmatics and discourse: A resource book for students. New York: Routledge Taylor \& Francis group.

Cheung, M. (2010). The globalization and localization of persuasive marketing communication: A cross-linguistic socio-cultural analysis. Journal of Pragmatics, 42(2), 354-376. doi:10.1016/j.pragma.2009.06.012

Cheung, M.L., Luo, C., Sia, C.L., \& Chen, H. (2009). Credibility of electronic word-of-mouth: Informational and normative determinants of on-line consumer recommendations. International Journal of Electronic Commerce, 13(4), 9-38.

Chu, S.C., \& Kim, Y. (2011). Determinants of consumer engagement in electronic word-ofmouth (eWOM) in social networking sites. International Journal of Advertising, 30(1), 4775.

Gee, P. J. (2005). An introduction to discourse analysis theory and method: Edition 2. New York: Routledge Taylor and Francis Group.

Gee, P. J. (2011). How to do a discourse analysis: A toolkit. New York: Routledge Taylor and Francis Group.

Grice, P. (1989). Studies in the way of words. Cambridge, Massachusetts: Harvard University Press. 


\section{WHAT IS THERE TO YELP ABOUT?}

Park, Lee, J., \& Han, I. (2007). The effect of on-line consumer reviews on consumer purchasing intention: The moderating role of involvement. International Journal of Electronic Commerce, 11(4), 125-148. doi:10.2753/JEC1086-4415110405

Steffes, E. M., \& Burgee, L. E. (2009). Social ties and online word of mouth. Internet Research, 19(1), 42.

Wilson, D., \& Sperber, D. "Truthfulness and Relevance." Mind 111, no. 443 (2002): 583-632.

Wilson D., \& Sperber D. Relevance theory. (2003). Relevance theory. In: Ward G, Horn L, editors. Handbook of Pragmatics (pp. 607-32). Oxford, UK: Blackwell Science.

Woods, N. (2006). Describing discourse: A practical guide to discourse analysis. New York, NY: Oxford University Press Inc.

Yelp. (2011). Yelp Elite squad. Retrieved from http://www.yelp.ca/elite 